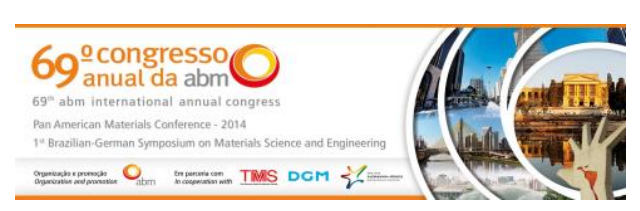

Tema: Tratamento térmico

\title{
CEMENTAÇÃO DO AÇO INOXIDÁVEL AISI 304 COM USO DE PLASMA FRIO*
}

\author{
Marcos Antonio Barcelos ${ }^{1}$ \\ João Batista Ribeiro Martins ${ }^{2}$ \\ Mariana Valinhos Barcelos ${ }^{2}$ \\ Renan Carreiro Rocha ${ }^{3}$ \\ Adonias Ribeiro Franco Junior ${ }^{4}$ \\ Estéfano Aparecido Vieira ${ }^{4}$
}

\section{Resumo}

O uso de tratamentos termoquímicos assistidos por plasma tem apresentado grande crescimento nos últimos anos em consequência dos excelentes resultados obtidos na modificação de superfícies em materiais de engenharia. Neste estudo será utilizado o aço inoxidável AISI 304 que apresenta boas características de resistência à corrosão, tendo vasto campo de aplicação nas indústrias têxteis e químicas. Será realizado tratamento termoquímico de cementação a plasma com temperatura fixa, variação de tempo e mistura gasosa $\left(\mathrm{CH}_{4}\right)$.

Palavras-chave: Cementação a plasma; Aço inoxidável AISI 304; Desgaste microabrasivo.

\section{CARURIZING AISI 304 STAINLESS STEEL WITH USE OF THE COLD PLASMA}

\begin{abstract}
The use of plasma assisted thermochemical treatments has shown steady growth in recent years due to the excellent results obtained in the modification of surfaces in engineering materials. In this study, AISI 304 stainless steel which has good corrosion resistance characteristics and wide application in textiles and chemical will be used. Will be held thermochemical treatment of the plasma with fixed carburizing temperature and time variation and gas mixture $\left(\mathrm{CH}_{4}\right)$.
\end{abstract}

Keywords: Plasma carburizing; Stainless steel AISI 304; Microabrasive wear.

1 Engenheiro Metalurgista e de Materiais, Aluno do Programa de Pós-Graduação em Engenharia Metalúrgica e de Materiais (PROPEMM), IFES, Vitória, ES, Brasil.

2 Mestre em Engenharia Metalúrgica e de Materiais, Professor, curso de Engenharia Metalúrgica e de Materiais, Departamento de Engenharia Metalúrgica, IFES, Vitória, ES, Brasil.

3 Mestre em Engenharia Metalúrgica e de Materiais, Professor, curso de Engenharia Mecânica, Coordenadoria de Engenharia Mecânica, IFES, São Mateus, ES, Brasil.

4 Doutor em Engenharia Metalúrgica e de Materiais, Professor, curso de Mestrado em Engenharia Metalúrgica e de Materiais, Departamento de Engenharia Metalúrgica, IFES, Vitória, ES, Brasil.

\footnotetext{
* Contribuição técnica ao $69^{\circ}$ Congresso Anual da ABM - Internacional e ao 14ํㅡㄹ ENEMET - Encontro Nacional de Estudantes de Engenharia Metalúrgica, de Materiais e de Minas, 21 a 25 de julho de 2014, São Paulo, SP, Brasil.
} 




\section{INTRODUÇÃO}

Os aços inoxidáveis possuem amplas aplicações na engenharia, principalmente nos setores alimentícios, aeronáuticos, ferroviários, petroquímicos e refrigeração. Apesar de sua grande aplicabilidade, em função de apresentar boa resistência à corrosão, a classe mais explorada destes materiais, a série 300 , não possui boa resistência ao desgaste e também dureza elevada quando comparada aos demais aços inoxidáveis. Desta série a liga metálica inoxidável mais popular é a classe 304, composto por aços austeníticos com estrutura cúbica de face centrada, oriunda de ligas contendo $\mathrm{Fe}-\mathrm{Cr}-\mathrm{Ni}$, com teores de $18 \%$ de $\mathrm{Cr}$ e $8 \%$ de $\mathrm{Ni}$ e máximo $0,08 \%$ de $\mathrm{C}$.

O grande desafio da área de Seleção de Materiais tem sido encontrar métodos que possam melhorar as propriedades mecânicas desses aços, atribuindo de forma satisfatória o emprego eficiente em escala industrial, onde parte-se de dois princípios a, reformulação de ligas metálicas e/ou aplicação de tratamentos termoquímicos.

Em meio aos possíveis tratamentos termoquímicos, a cementação em metais com baixa temperabilidade é um dos processos mais utilizados em aços de teores de $\mathrm{C}$, cujo objetivo principal é melhorar as características superficiais, através da difusão de carbono, melhorando a resistência ao desgaste, bem como, aumentando a dureza superficial do material, no caso de aços inoxidáveis austeníticos pesquisas demostraram que a cementação realizada em temperaturas menores que $450^{\circ} \mathrm{C}$ proporcionam ganhos consideráveis nas propriedades mecânicas sem interferir na resistência a corrosão [2-6].

Neste estudo é proposto um tratamento termoquímico de cementação a plasma na temperatura de $410^{\circ} \mathrm{C}$, mistura gasosa com concentração de $7 \%$ de $\mathrm{CH}_{4}$ e $93 \%$ de $\mathrm{H}_{2}$, num tempo de três horas e variação de tempo de 1 à 8 horas, considerando que não foram encontrados muitos estudos relacionados ao tratamento de cementação à plasma a baixas temperaturas nos aços inoxidáveis austeníticos AISI 304.

\section{MATERIAIS E MÉTODOS}

\subsection{Materiais}

O material escolhido foi o aço inoxidável austenítico AISI 304, por ser uma liga com poucos estudos na área de tratamentos termoquímicos de cementação à plasma a baixas temperaturas, no experimento foram usadas amostras cortadas de uma barra cilíndrica com diâmetro de 1/8 de polegada e espessura de aproximadamente $3,5 \mathrm{~mm}$, conforme composição química descrita na Tabela 1, podendo-se observar a coerência da composição, conforme estabelecido pela (American Society for Metals) ASM [3].

Tabela 1. Composição química para o aço AISI 304 nominal conforme a ASM e medido [1]

\begin{tabular}{ccccccccc}
\hline \multirow{2}{*}{ Tipo } & UNS & \multicolumn{8}{c}{ Composição (\%) } \\
& Designation & $\mathrm{C}$ & $\mathrm{Mn}$ & $\mathrm{Si}$ & $\mathrm{Cr}$ & $\mathrm{Ni}$ & $\mathrm{P}$ & $\mathrm{S}$ \\
\hline AISI 3041 & $\mathrm{S} 30400$ & $0,08^{*}$ & $2,0^{*}$ & 1,00 & $18-20$ & $8-10,5$ & $0,045^{*}$ & $0,03^{*}$ \\
Medido & -- & 0,08 & 1,92 & 1,00 & 18,00 & 8,34 & 0,040 & 0,02 \\
\hline *limite máximo. & & & & & & & &
\end{tabular}

\footnotetext{
* Contribuição técnica ao $69^{\circ}$ Congresso Anual da ABM - Internacional e ao 14ํㅡㄹ ENEMET - Encontro Nacional de Estudantes de Engenharia Metalúrgica, de Materiais e de Minas, 21 a 25 de julho de 2014, São Paulo, SP, Brasil.
} 


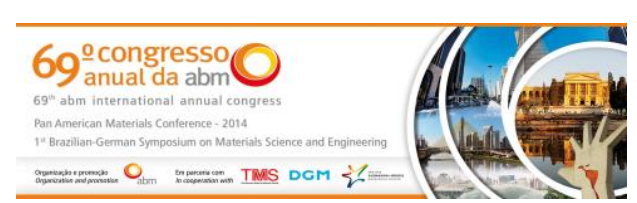

\subsection{Métodos}

Os procedimentos experimentais e as análises pertinentes a serem desenvolvidas durante o referido estudo foram conforme a Figura 1.

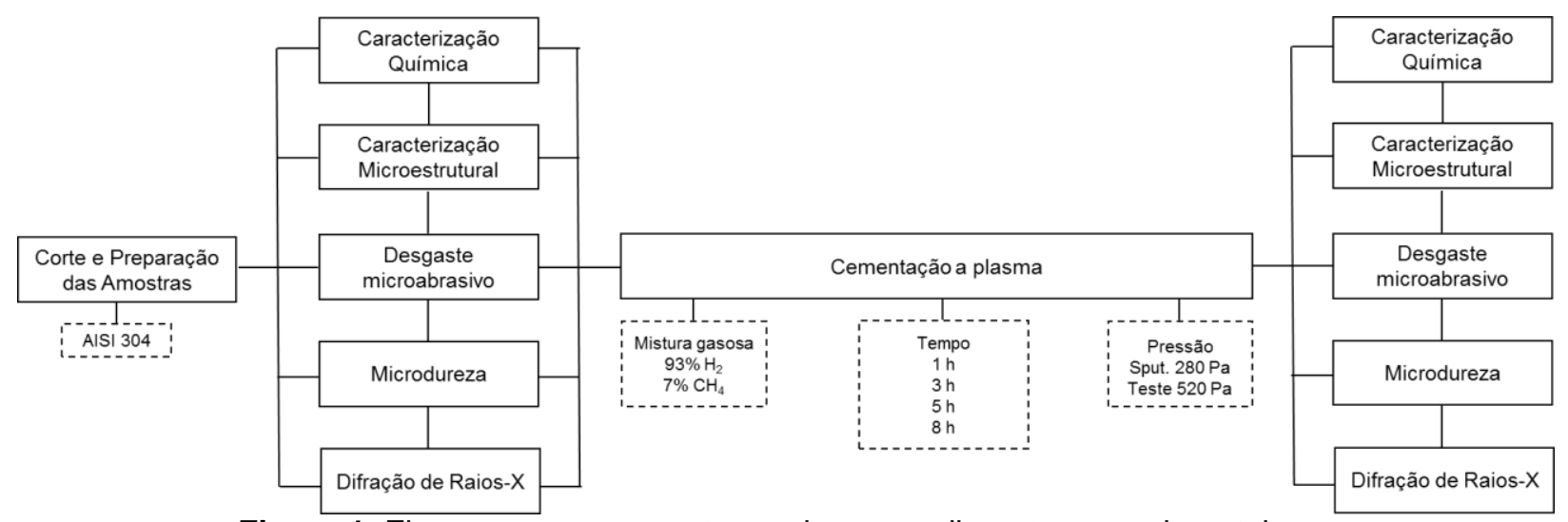

Figura 1. Fluxograma com as etapas dos procedimentos experimentais.

O tratamento termoquímico foi realizado em forno a plasma pulsado da marca SDS modelo Thor NP 500, com capacidade de operação de $50 \mathrm{~kg}$, sendo que após tratadas, às amostras foram preparadas metalograficamente e analisadas em microscopia óptica com ataque de água régia, desgaste microabrasivo realizado no equipamento de microabrasão do tipo "esfera livre" da marca CSM Instruments, avaliação da microdureza do substrato e da camada cementada por meio do microdurômetro Digital Microhardness Tester HMV-G com cargas de $2,5 \mathrm{~g}$ e difratograma de Raios-x realizados no equipamento difratômetro Bruker D-phaser, do Laboratório de Engenharia de Superfícies do Departamento de Engenharia Metalúrgica do IFES.

As amostras após cortadas foram retificadas gerando uma espessura de aproximadamente $3,0 \mathrm{~mm}$ cada, depois preparadas segundo técnicas metalográficas convencionais de lixamento $(80,180,220,320,400,600,1000$ e 1200 mesh) e polimento (alumina de 1 e $0,3 \mu \mathrm{m}$ ), concluído os procedimentos de corte, lixamento e polimento das amostras as mesmas foram levadas ao forno e realizado o procedimento de limpeza com argônio (sputtering), na temperatura de $370^{\circ} \mathrm{C} / 0,5 \mathrm{~h}$ e pressão de 3,9torr (520Pa), visando remover a camada de óxido de cromo $\left(\mathrm{Cr}_{2} \mathrm{O}_{3}\right)$ da superfície da amostra.

$\mathrm{O}$ tratamento termoquímico foi realizado a uma temperatura de $410^{\circ} \mathrm{C}$ nos tempos de $1 \mathrm{~h}, 2 \mathrm{~h}, 5 \mathrm{~h}$ e $8 \mathrm{~h}$ (duas amostras para cada condição de tratamento), em uma atmosfera composta por $93 \% \mathrm{H}_{2}$ e $7 \% \mathrm{CH}_{4}$, com pressão interna de trabalho fixada em 5,1torr $(680 \mathrm{~Pa})$, com resfriamento realizado dentro do próprio reator até a temperatura ambiente.

Foi realizado exame metalográfico da secção transversal da matriz e das amostras cementadas, visando avaliar a camada cementada, observar a zona de difusão, além da interface camada cementada/substrato, onde os discos foram cortados perpendicularmente à superfície tratada e a superfície gerada com espessura de aproximadamente $3 \mathrm{~mm}$ foi embutida em baquelite, na preparação da superfície a ser observada o procedimento adotado foi o mesmo já descrito anteriormente até chegar ao polimento com alumina de $0,3 \mu \mathrm{m}$, adicionalmente a superfície foi atacada com água régia para revelar a microestrutura formada, após tal procedimento as amostras foram levadas ao microscópico ótico modelo Metaluxx 3, marca Leitz do

\footnotetext{
* Contribuição técnica ao $69^{\circ}$ Congresso Anual da ABM - Internacional e ao 14ํㅡㄹ ENEMET - Encontro Nacional de Estudantes de Engenharia Metalúrgica, de Materiais e de Minas, 21 a 25 de julho de 2014, São Paulo, SP, Brasil.
} 


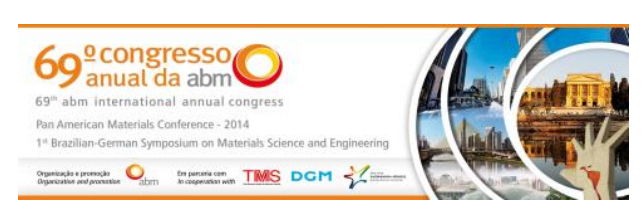

Laboratório de Engenharia de Superfícies do Departamento de Engenharia Metalúrgica do IFES e micrografias foram obtidas para os diversos tratamentos realizados, o desgaste microabrasivo foi realizado no equipamento de microabrasão do tipo "esfera livre" da marca CSM Instruments, onde os ensaios foram realizados conforme metodologia proposta por Rutherford e Hutchings [7]. Neste teste foi utilizado uma esfera confeccionada a partir do aço AISI 5120 com diâmetro de $25,4 \mathrm{~mm}$, os coeficientes de desgaste (K), foram medidos utilizando-se como abrasivo, lama de carbeto de silício (SIC) numa concentração $0,75 \mathrm{~g} / \mathrm{cm} 3$, granulometria de aproximadamente $5 \mu \mathrm{m}$, vazão de alimentação de 1 gota/cada 3 segundos. A carga aplicada nos testes foi de $0,27 \mathrm{~N}( \pm 0,02)$, com rotação do motor de 150RPM e intervalos de avaliação das crateras desgastadas de 5, 15, 30, 45 e 60 minutos, onde em cada bateria de amostras foi possível gerar o coeficiente de desgaste a partir da media aritmética dos coeficientes, obtidos após a taxa de desgaste permanecer constante (running-in). As calotas foram fotografadas em um microscópio ótico e feitas posterior medição dos diâmetros. A análise dos resultados foi realizada plotando-se a o coeficiente de desgaste em $(K)$ em função do tempo. A perda de massa, ou seja, volume $(\mathrm{V})$ foi calculado em função da distancia percorrida em metros (L) e é dado em [mm3] conforme a Equação 1 [5,7]:

$$
V=\frac{\pi \cdot b^{4}}{32 . \mathrm{L}}
$$

onde "b" é o diâmetro da calota de desgaste dado em mm, "D" é o diâmetro da esfera utilizada dado em mm. Já o coeficiente de desgaste $\mathrm{K}$ dado em $\left[\mathrm{m}^{2} \cdot \mathrm{N}^{-1}\right]$ pode ser calculado usando-se a Equação 2:

$$
\mathrm{K}=\frac{\mathrm{V}}{\mathrm{L} \cdot \mathrm{F}_{\mathrm{N}}}
$$

onde "FN" é a força normal aplicada no ensaio dado em $N$ e "L" é a distância de deslizamento dada em $\mathrm{mm}$ e pode ser calculada conforme Equação 3:

$$
\mathrm{L}=\frac{19,95 . \mathrm{n}}{\sqrt{\frac{\mathrm{D}^{2}}{4}-25}}
$$

O valor de "n" é o número de voltas realizadas pelo eixo motor do equipamento de ensaio.

Para avaliar o grau de endurecimento das superfícies cementadas e mediu-se a dureza de topo e perfil utilizando carga de $2,5 \mathrm{~g}$ e identador Vickers, pelas mesmas metodologias já descritas. Também foi avaliado o difratograma de raio- $x$ da amostras cementadas comparado com a matriz. O valor de " $n$ " é o número de voltas realizadas pelo eixo motor do equipamento de ensaio.

\section{RESULTADOS E DISCUSSÃO}

A Figura 2 mostra a evolução da camada cementada em função do tempo de tratamento. Os resultados mostram um aumento da espessura em relação ao tempo de tratamento, onde a máxima conseguida foi de $15,7 \mu \mathrm{m}$ para $8 \mathrm{~h}$ de tratamento. $\mathrm{A}$ Figura 3 mostra o mesmo resultado e pode-se perceber que à medida que se aumenta a espessura da camada cementada tem-se uma menor eficiência de

\footnotetext{
* Contribuição técnica ao $69^{\circ}$ Congresso Anual da ABM - Internacional e ao 14ํㅡㄹ ENEMET - Encontro Nacional de Estudantes de Engenharia Metalúrgica, de Materiais e de Minas, 21 a 25 de julho de 2014, São Paulo, SP, Brasil.
} 


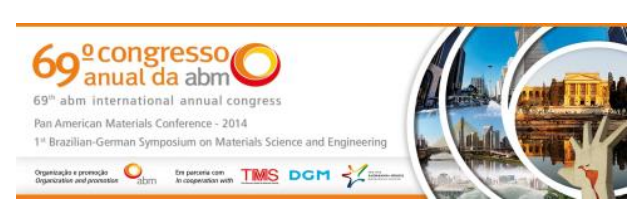

formação, isto pode ser explicado porque o processo de difusão na camada já formada é bem menor do que na austenita e que outros fenômenos além da difusão do carbono podem também estar ocorrendo como, por exemplo, a presença da fase austenita saturada de carbono. Por outro lado, conforme observado em outros trabalhos, algumas fases "escuras" podem forma-se próximo a superfície, formação esta associada à precipitação de carbonetos de cromo, o que conduz a uma degradação da resistência a corrosão [6]. Para produção de camadas cementadas espessas, embora o aumento da temperatura seja o procedimento mais eficaz existe a limitação no que diz respeito ao favorecimento da precipitação destes carbonetos [7].

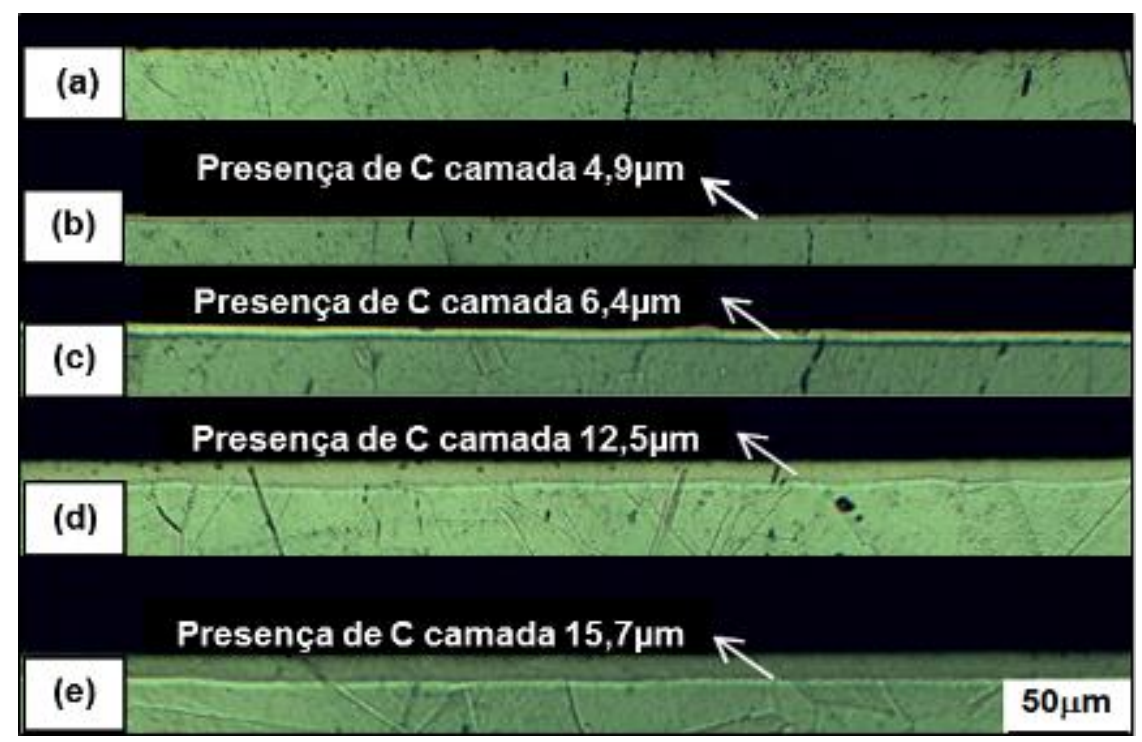

Figura 2. Evolução da camada cementada a plasma a $410^{\circ} \mathrm{C}$ em função do tempo de tratamento (a) sem tratamento (b) $1 \mathrm{~h} \mathrm{(c)} 2 \mathrm{~h} \mathrm{(d)} 5 \mathrm{~h}(\mathrm{e}) 8 \mathrm{~h}$. Atmosfera composta por $7 \%$ de $\mathrm{CH}_{4(\mathrm{~g})}$ e $93 \%$ de $\mathrm{H}_{2(\mathrm{~g}) \text {. }}$. M.O. 200x.

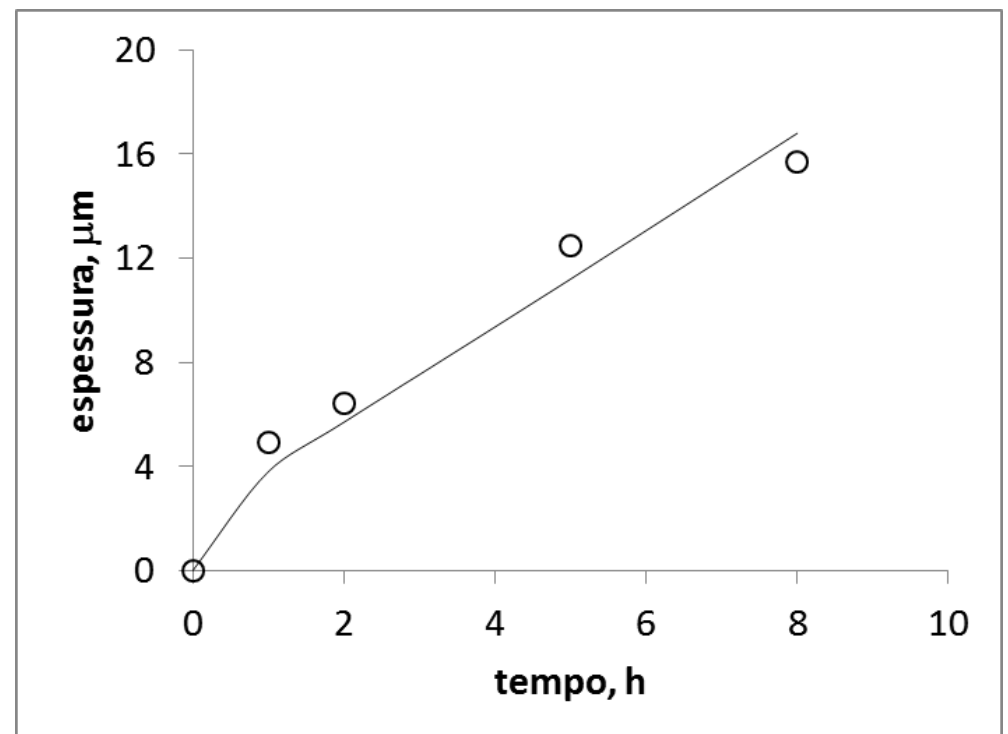

Figura 3. Evolução da camada cementada a plasma a $410^{\circ} \mathrm{C}$ em função do tempo de tratamento.

A Figura 4 apresenta uma típica imagem de uma calota obtida experimentalmente após o final do ensaio de desgaste microabrasivo. As medidas realizadas utilizandose um microscópio ótico mostram que o diâmetro final da calota é maior quando o

\footnotetext{
* Contribuição técnica ao 69ำ Congresso Anual da ABM - Internacional e ao 14ํㅡㄹ ENEMET - Encontro Nacional de Estudantes de Engenharia Metalúrgica, de Materiais e de Minas, 21 a 25 de julho de 2014, São Paulo, SP, Brasil.
} 


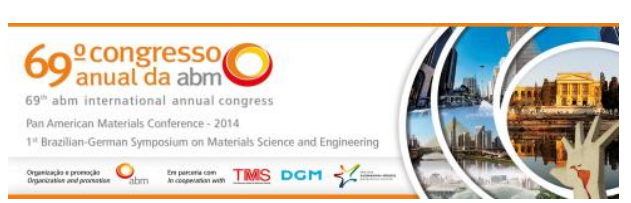

tempo de tratamento é maior. A Figura $4 \mathrm{~b}$ mostra os diâmetros finais das calotas obtidas em função do tempo de tratamento termoquímico. Observa-se que a queda do diâmetro da calota corresponde ao aumento de espessura alcançada pelo tratamento termoquímico. Este resultado mostra que o aumento da espessura cementada melhora a resistência ao desgaste.

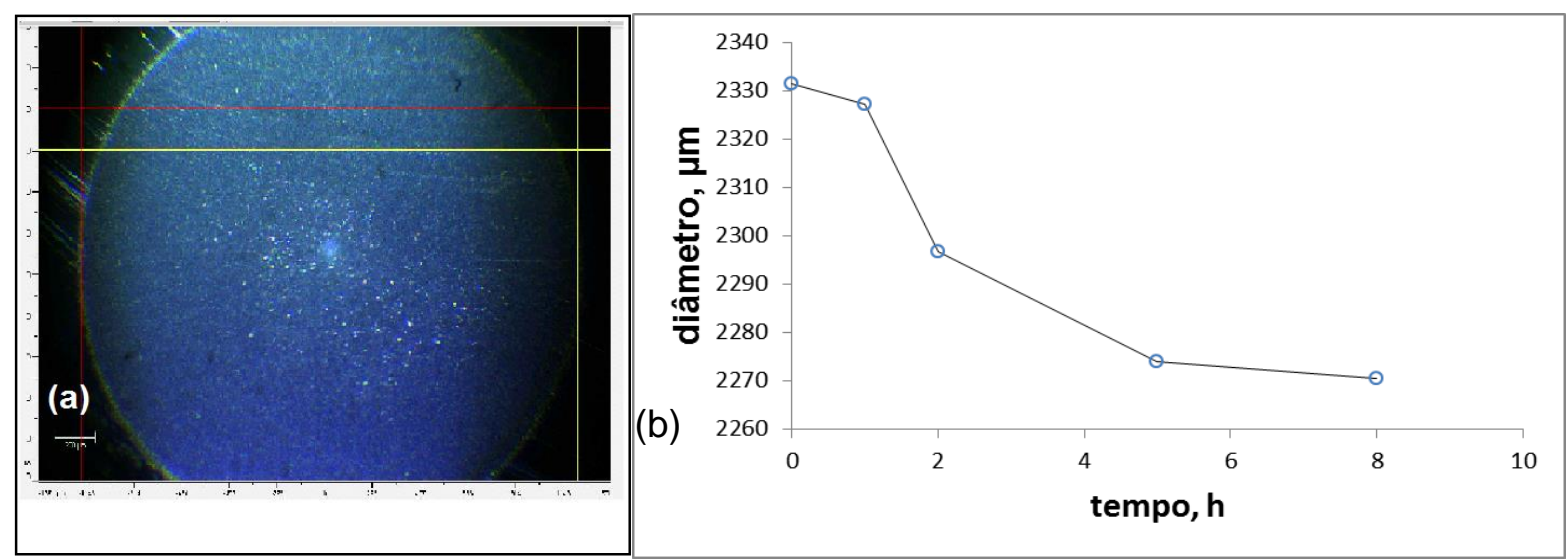

Figura 4. Típica calota esférica obtida no ensaio de desgaste microabrasivo (a) e diâmetro da calota em função do tempo de tratamento térmico (b).

A Figura 5 mostra os valores dos coeficientes de desgaste "K" calculados a partir dos resultados experimentais e confirma-se que o experimento de $8 \mathrm{~h}$ foi superior aos demais tempos de tratamento, ou seja, 1, 2 e $5 \mathrm{~h}$. Embora se tenha um aumento da espessura da camada cementada nos tempos de 5 para 8 horas de tratamento, esta por sua vez, parece não trazer melhorias significativas, apenas $1,5 \%$. Os experimentos demostram que tratamento superiores a 5 horas a partir desta mistura gasosa servem apenas para aumentar custo do processo do ponto de vista de resistência ao desgaste. Adicionalmente podemos perceber através dos coeficientes "K" obtidos que o tratamento termoquímico de cementação foi eficiente para melhorar a resistência ao desgaste, pois, em todas as situações seu valor foi inferior quando comparado com o coeficiente obtido para a amostra não tratada.

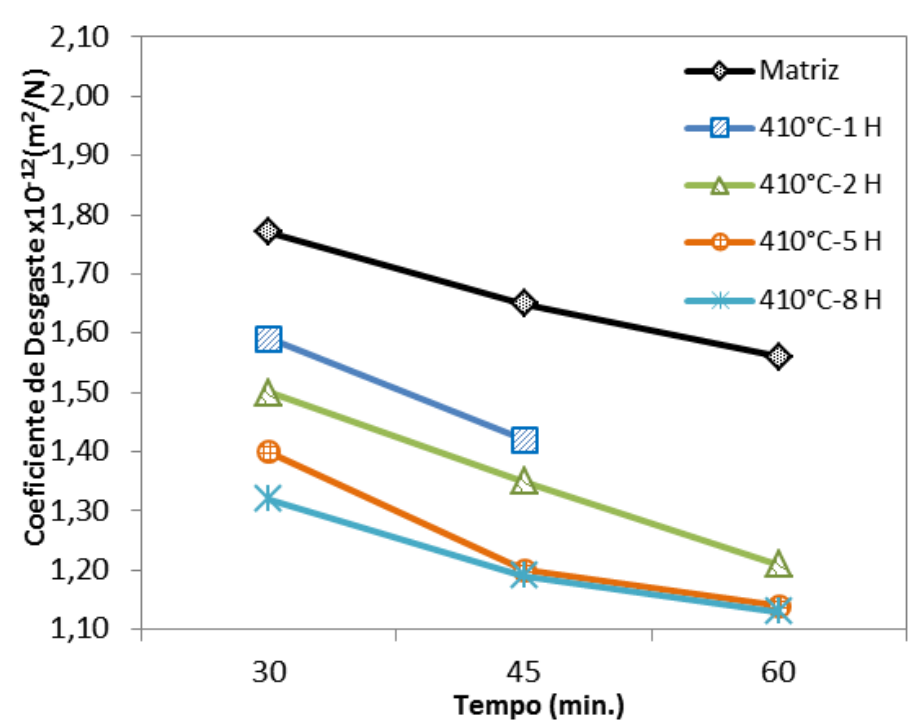

Figura 5. Curva de taxa de desgaste "K" em função do tempo para o aço AISI 304 não tratado e cementado a plasma a $410^{\circ} \mathrm{C}$ por tempos variando de $1 \mathrm{~h}$ a $8 \mathrm{~h}$.

\footnotetext{
* Contribuição técnica ao 69ำ Congresso Anual da ABM - Internacional e ao 14ํㅡㄹ ENEMET - Encontro Nacional de Estudantes de Engenharia Metalúrgica, de Materiais e de Minas, 21 a 25 de julho de 2014, São Paulo, SP, Brasil.
} 


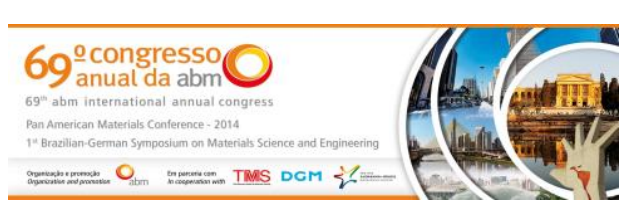

Na Figura 6 são apresentados os resultados de perfil de microdureza das camadas cementadas, onde todas as camadas apresentaram dureza maior que o substrato não cementado, a carga ulitizada foi de $2,5 \mathrm{~g}$, não sendo observado interferência do substrato.

Os maiores valores encontrados foram os correspondentes aos tempos de 5 e 8 horas, onde obteve-se respectivamente os valores de $482 \mathrm{HV}_{0,025}$ e $528 \mathrm{HV}_{0,025}$, provavelmente em função da proximidades dos valores obtidos da camada cementada $(12,5$ e $15,7 \mu \mathrm{m})$. Os resultados de desgaste mostram que essas camadas apresentam valores de coeficiente de desgaste muito próximos $1,15 \times 10^{-12}\left[\mathrm{~m}^{2} \cdot \mathrm{N}^{-1}\right]$ e $1,13 \times 10^{-12}\left[\mathrm{~m}^{2} . \mathrm{N}^{-1}\right]$, respectivamente. Isso indica que o uso de tempos prolongados de cementação usando $7 \%$ de $\mathrm{CH}_{4(\mathrm{~g})}$ e $93 \%$ de $\mathrm{H}_{2(\mathrm{~g})}$ na temperatura de $410^{\circ} \mathrm{C}$ não foram efetivos nos resultados da resistência ao desgaste do material.

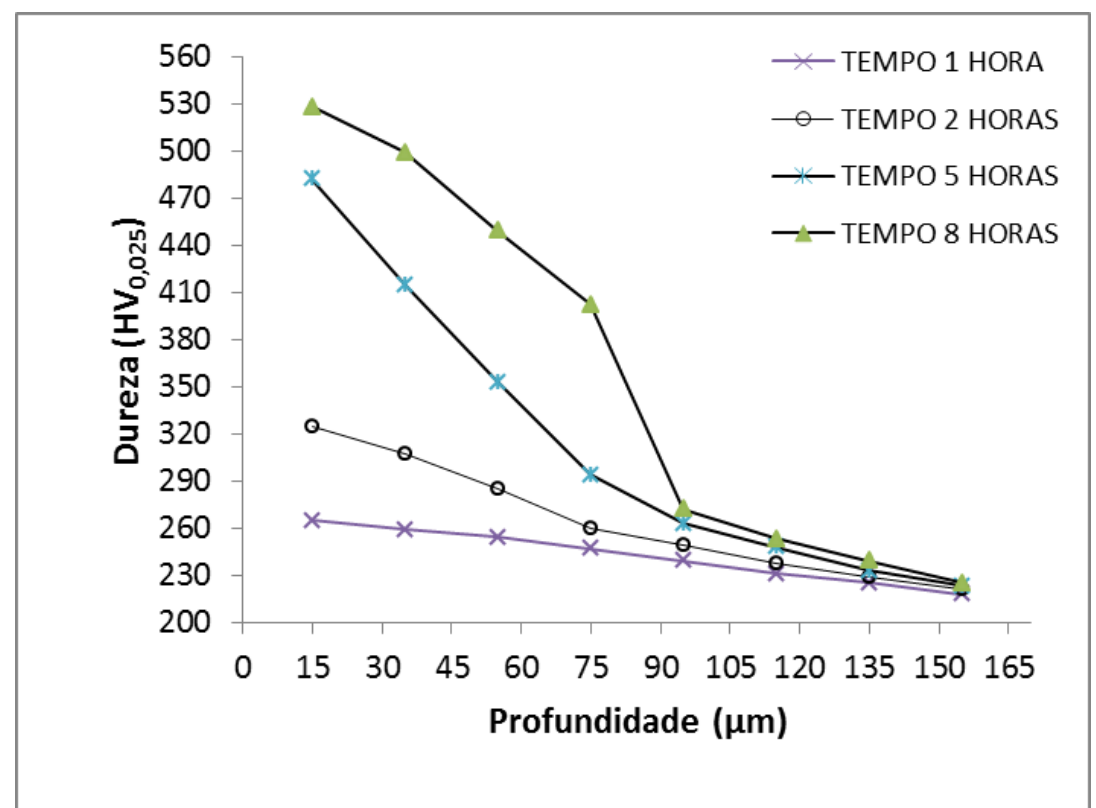

Figura 6. Perfil de dureza das camadas após tratamento de cementação a plasma para o aço AISI 304 a $410^{\circ} \mathrm{C}$.

Na Figura 7 são apresentados difratogramas de raios- $X$ da matriz e das amostras após a cementação, notando que não há a presença de picos que identifiquem a presença de carbonetos nas camadas, além disso, nota-se em todas as amostras tratadas picos identificadores de austenita deslocados para a esquerda, ou seja, para ângulos menores, o que torna evidente uma expansão do reticulado em função do acréscimo da quantidade de carbono, mostrando a fase de austenita expandida, característica das fases com supersaturação do carbono [8].

\footnotetext{
* Contribuição técnica ao $69^{\circ}$ Congresso Anual da ABM - Internacional e ao 14ํㅡㄹ ENEMET - Encontro Nacional de Estudantes de Engenharia Metalúrgica, de Materiais e de Minas, 21 a 25 de julho de 2014, São Paulo, SP, Brasil.
} 

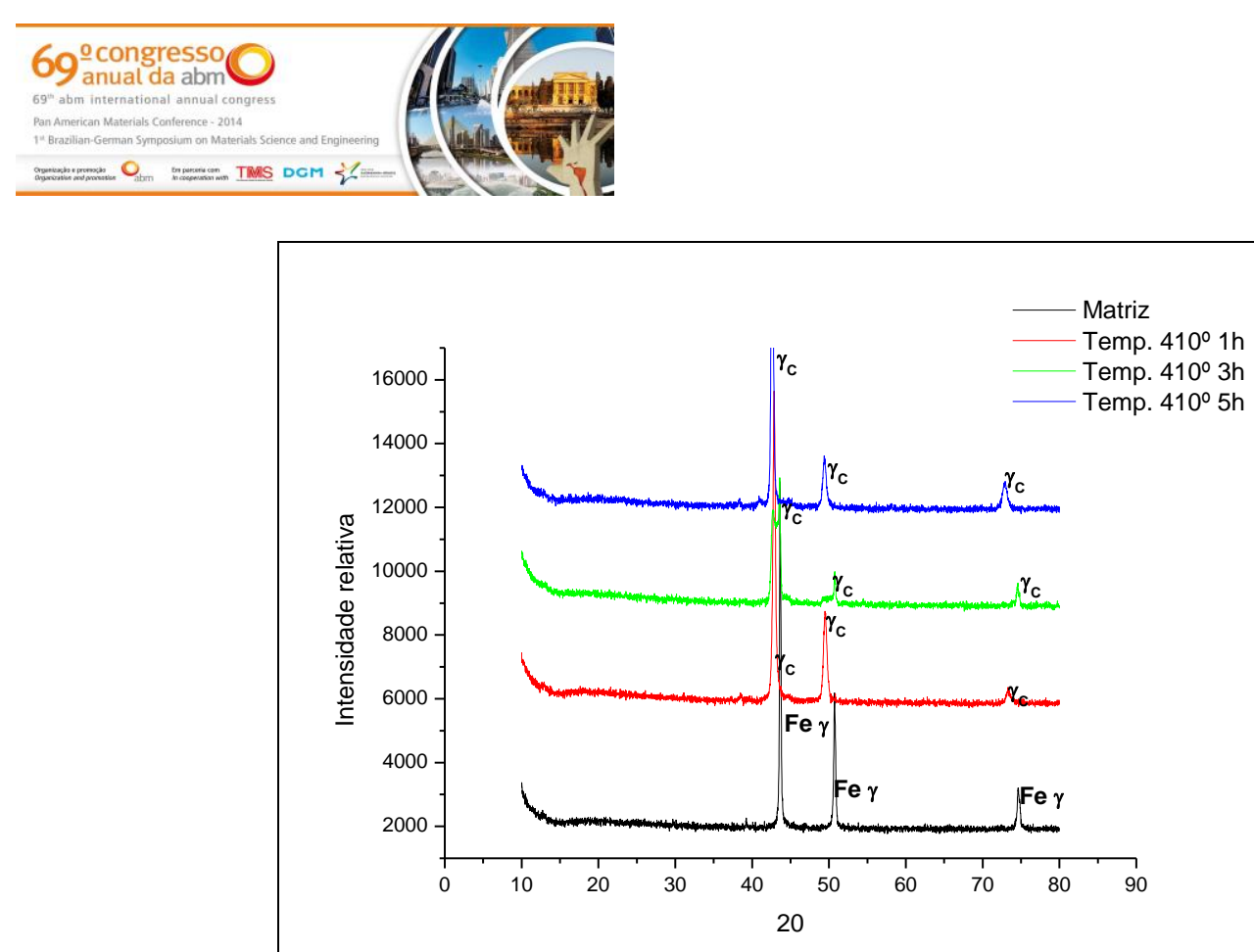

Figura 7. Perfil de dureza das camadas após tratamento de cementação a plasma para o aço AISI 304 a $410^{\circ} \mathrm{C}$.

\section{CONCLUSÃo}

O presente trabalho mostrou que é possível melhorar as propriedades tribológicas do aço AISI 304 através do tratamento termoquímico de cementação a plasma.

$\mathrm{O}$ aumento do tempo de cementação a plasma favorece a produção de uma maior espessura de camada cementada, no entanto, o uso de tempos de cementação superiores às $5 \mathrm{~h}$ possibilitam ganhos pouco significativos de espessura considerando o tempo despendido no tratamento.

As camadas mais espessas, de 12,5 e $15,7 \mu \mathrm{m}$ de espessura, apresentaram os melhores resultados de desgaste. Em relação ao material não cementado, ocorreu uma redução no coeficiente de desgaste de aproximadamente $30 \%$.

Os ganhos alcançados foram evidenciados com os resultados obtidos nos espectros de DRX sugerindo a presença da formação de austenita expandida ou fase $S$ de carbono em todas as condições avaliadas, sem evidência deformação de carbonetos de carbono, $\mathrm{FeC}, \mathrm{Fe}_{2} \mathrm{C}$ e $\mathrm{Fe}_{5} \mathrm{C}_{2}$, elementos indesejáveis ao processo.

\section{REFERÊNCIAS}

1 Silva ALVC. Aços e Ligas Especiais. 3aㅡ edição. São Paulo: Editora Blücher; 2011.

2 Dong H, Qi P-Y, Li XY, Llewellyn RJ. Improving the erosion-corrosion resistance of AISI 316 austenitic stainless stell by low-temperature plasma surface alloying with $\mathrm{N}$ and $\mathrm{C}$. Materials Science Engineering A. 2006;431:137-145.

3 ASM Committee on Gas Carburizing. Carburizing and Carbonitriding. Metals Park: American Society Metals; 1977.

4 Sun Y. Kinetics of low temperature plasma carburizing of austenitic stainless steels. Journal of Materials Processing Technology. 2005;168:189-194.

5 Aggen G, et al. ASM Handbook - Properties and Selection: Stainless Steels, Tools Materials and Special-Purpose Metals. vol. 3. ASM International; 1987.

6 Gee MG, Gant AJ, Hutchings IM, Kusano Y, Schiffman K, Acker VK., et al. Results from an interlaboratory exercice to validade the micro-scale abrasion test. Wear. 2005;259:27-35.

\footnotetext{
* Contribuição técnica ao $69^{\circ}$ Congresso Anual da ABM - Internacional e ao 14ํㅡㄹ ENEMET - Encontro Nacional de Estudantes de Engenharia Metalúrgica, de Materiais e de Minas, 21 a 25 de julho de 2014, São Paulo, SP, Brasil.
} 
7 Rutherford KL, Hutchings IM. A micro-abrasive wear test, with particular application to coated systems. Surface and Coatings Technology.1996;79(1-3):231-239.

8 Gobbi SJ, Santos CB, Jacques R, Teischmann L, Strohecker TRJ, Ferreira JZ. Endurecimento superficial dos aços AISI 316L e AISI 304 por cementação a plasma em baixas temperaturas. In: Congresso Brasileiro de Engenharia e Ciência dos Materiais; 2006; Foz do Iguaçu, Brasil. 2006.

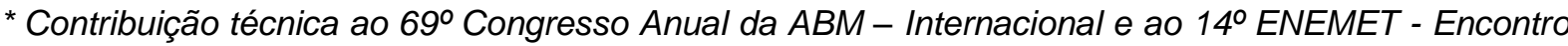
Nacional de Estudantes de Engenharia Metalúrgica, de Materiais e de Minas, 21 a 25 de julho de 2014, São Paulo, SP, Brasil. 